\title{
CORRESPONDENCE
}

\section{Non-natives: 141 scientists object}

We the undersigned feel that in advocating a change in the environmental management of introduced species (Nature 474, 153-154; 2011), Mark Davis and colleagues assail two straw men.

First, most conservation biologists and ecologists do not oppose non-native species per se - only those targeted by the Convention on Biological Diversity as threatening "ecosystems, habitats or species". There is no campaign against all introductions: scarcity of resources forces managers to prioritize according to the impact of troublesome species, as in the Australian Weed Risk Assessment.

Second, invasion biologists and managers do not ignore the benefits of introduced species. They recognize that many nonnative species curtail erosion and provide food, timber and other services. Nobody tries to eradicate wheat, for instance. Useful non-native species may sometimes still need to be managed because they have a negative impact, such as tree invasions that cause water loss in the South African fynbos.

Davis and colleagues downplay the severe impact of non-native species that may not manifest for decades after their introduction - as occurred with the Brazilian pepper shrub (Schinus terebinthifolius) in Florida (J. J. Ewel in Ecology of Biological Invasions of North America and Hawaii (eds H. A. Mooney and J. A. Drake) 214-230; Springer, 1986). Also, some species may have only a subtle immediate impact but affect entire ecosystems, for example through their effect on soils.

Pronouncing a newly introduced species as harmless

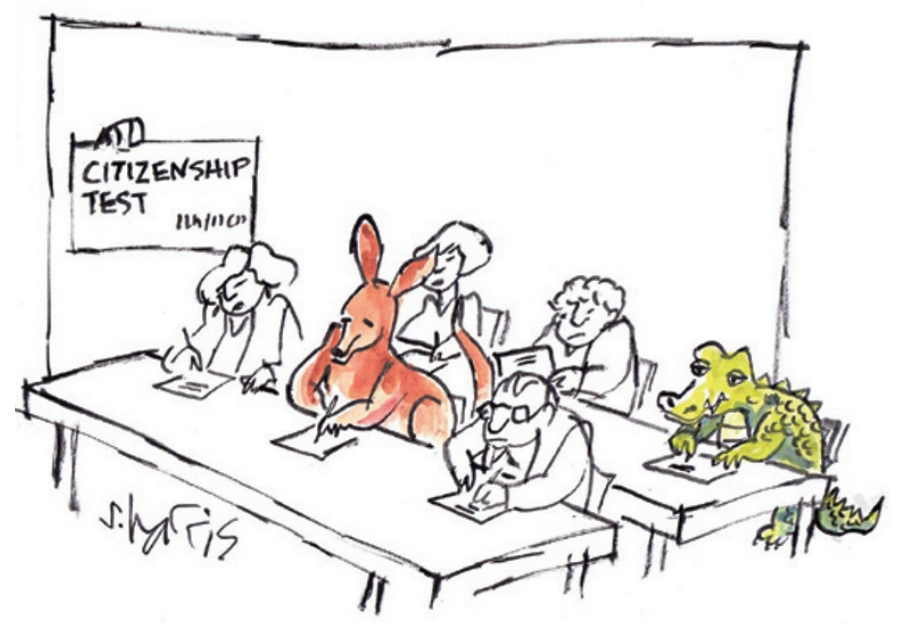

can lead to bad decisions about its management. A species added to a plant community that has no evolutionary experience of that organism should be carefully watched.

For some introductions, eradication is possible. For example, 27 invasive species have been eradicated from the Galapagos Islands, mitigating severe adverse effects on endemic species. Harmful invasive species have been successfully kept in check by biological, chemical and mechanical means.

The public must be vigilant of introductions and continue to support the many successful management efforts.

Daniel Simberloff ${ }^{\star}$ University of Tennessee, Tennessee, USA. dsimberloff@utk.edu ${ }^{*}$ On behalf of 141 signatories (see go.nature.com/f1eqjn).

\section{Non-natives: put biodiversity at risk}

Bias against non-native species is not xenophobic (Nature 474, 153-154; 2011) - it has a sound scientific foundation.

The non-native status of a species is highly relevant to assessing its potential environmental and economic impact. Unrestrained growth and environmental damage follow when there are no natural enemies in newly colonized areas. This is not necessarily a sign of an invader's superior evolutionary fitness: it may lead to a population collapse due to overexploitation of resources.

Non-native species can increase the variety of species in a community, but it is an oversimplification to equate this with increased biodiversity, of which species richness is only one component. Surviving populations of native species may shrink or become restricted to poor-quality marginal habitats. Such unevenness hardly contributes to a more diverse community.

The genetic diversity of invaded communities may decrease because of bottlenecks: native genotypes disappear as populations fall, whereas the invaders originate from very few initial colonizers.

Establishment of non-native species inevitably decreases global diversity. Australia, for example, was unique in having no placental mammals; their introduction by humans made the continent ecologically more similar to the rest of the world. Andrei Alyokhin University of Maine, Maine, USA.

andrei.alyokhin@umit.maine.edu
Non-natives: plusses of invasion ecology

Contrary to the implications of Mark Davis and colleagues (Nature 474, 153-154; 2011), invasion ecology has given us valuable insight into the effects of new species on ecological function and into some of the precipitous changes we may face in the coming decades.

Invasion ecologists generally assert that only a very small fraction of non-native species harm their new ecosystems. This position emerged as early as 1986 and was mainstream in the era that Davis and colleagues claim as the nadir of ecological nativism.

It is unfair to characterize any scientific discipline solely by past failures and to ignore its successes. Invasion ecology is making real progress with defining impact and characterizing risk. Let's not throw up our hands in despair just yet.

Julie L. Lockwood Rutgers, The State University of New Jersey, USA. lockwood@aesop.rutgers.edu Martha F. Hoopes Mount Holyoke College, Massachusetts, USA.

Michael P. Marchetti California State University, California, USA.

\section{Non-natives: four risk factors}

Mark Davis et al. set an unrealistically high bar for those making management decisions about exotic species (Nature 474, 153-154; 2011). Control is often easier, cheaper and more effective soon after detection (R. A. Haack et al. Annu. Rev. Entomol. 55, 521-546; 2010). We agree that research on ecosystem impact is necessary, but such studies can take years.

Meanwhile, we suggest that 